\title{
Development of an operational coastal flooding early warning system
}

\author{
D.-J. Doong ${ }^{1}$, L. Z.-H. Chuang ${ }^{2}$, L.-C. Wu ${ }^{3}$, Y.-M. Fan ${ }^{3}$, C. C. Kao ${ }^{3}$, and J.-H. Wang ${ }^{4}$ \\ ${ }^{1}$ Department of Marine Environmental Informatics and Center of Excellence for Marine Bioenvironment and Biotechnology, \\ National Taiwan Ocean University, Keelung, Taiwan \\ ${ }^{2}$ Institute of Ocean Technology and Marine Affairs, National Cheng Kung University, Tainan, Taiwan \\ ${ }^{3}$ Coastal Ocean Monitoring Center, National Cheng Kung University, Tainan, Taiwan \\ ${ }^{4}$ Water Resources Agency, Taipei, Taiwan \\ Correspondence to: D.-J. Doong (doong@mail.ntou.edu.tw)
}

Received: 3 October 2011 - Revised: 12 December 2011 - Accepted: 20 December 2011 - Published: 17 February 2012

\begin{abstract}
Coastal floods are a consistent threat to oceanfront countries, causing major human suffering and substantial economic losses. Climate change is exacerbating the problem. An early warning system is essential to mitigate the loss of life and property from coastal flooding. The purpose of this study is to develop a coastal flooding early warning system (CoFEWs) by integrating existing sea-state monitoring technology, numerical ocean forecasting models, historical database and experiences, as well as computer science. The proposed system has capability of offering data for the past, information for the present and future. The system was developed for the Taiwanese coast due to its frequent threat by typhoons. An operational system without any manual work is the basic requirement of the system. Integration of various data sources is the system kernel. Numerical ocean models play an important role within the system because they provide data for assessment of possible flooding. The regional wave model (SWAN) that nested with the large domain wave model (NWW III) is operationally set up for coastal wave forecasting, in addition to the storm surge predicted by a POM model. Data assimilation technology is incorporated for enhanced accuracy. A warning signal is presented when the storm water level that accumulated from astronomical tide, storm surge, and wave-induced run-up exceeds the alarm sea level. This warning system has been in practical use for coastal flooding damage mitigation in Taiwan for years. An example of the system operation during the Typhoon Haitung which struck Taiwan in 2005 is illustrated in this study.
\end{abstract}

\section{Introduction}

The northwestern part of the Pacific Ocean globally features numerous and intense tropical cyclones (typhoons). With strong wind entering the coast, the direct force by huge waves and rising sea levels caused by storm surges resulting from typhoons destruct the coastal defense, accelerate the coastal erosion, and cause coastal flooding directly or indirectly. Coastal inhabitants are exposed to such hazards. Taiwan's location is on the major moving track of typhoons in the NW Pacific. Coastal flooding is frequent during typhoon season in Taiwan. Every year the property damage costs due to typhoons are estimated in the hundreds of millions of dollars. Development of a system for early warning on coastal flooding is therefore necessary for loss reduction. Nowadays, the technologies of sea state monitoring and numerical prediction models are well developed. Information and communication technologies are also sufficient. Application of such scientific principle to establish a coastal flooding warning system is possible and is the task of this study.

In the past, warnings for natural disasters were first reported by people who witnessed signs of impending danger, such as the sea surface rising at the coast. This mode of detection provided little opportunity for people to seek shelter and avoid injury or death. The number of avoidable and unnecessary deaths and property damage could be reduced dramatically with an effective early warning system. Over the last several decades, scientists have progressed considerably in understanding the causative effects of natural disasters that have a great impact on lives. Although they cannot yet predict disasters fully, countries now possess the technical ability to detect and track them with impressive accuracy. 
Warning systems for river flooding are numerous (Parker and Fordham, 1996; Wang and Du, 2003; Plessis, 2002; Kaya et al., 2005; Basha and Rus, 2007). For coastal areas, substantial efforts have been invested into the different management systems (Solomon and Forbes, 1999; Doornkamp, 1998; Thumerer et al., 2000). In the aftermath of the 2004 Indian Ocean tsunami, the warning system was developed (Nayak and Kumar, 2008; Taubenböck et al., 2009). Most of the presented warning have a rigid theoretical base, but some of them lack an operational interface. A correct, direct, and simple warning system is useful for the decision marker to receive valuable information. Currently, such a system can be implemented by applying latest computer technologies. Holz et al. (2006) presented an application of information and communication technology to provide improved flood detection capabilities for citizens. Katuk et al. (2009) presented the development of a web-based support system for flood response operations in Malaysia to provide prompt and effective response to victims. Wang and Du (2003) developed a flood warning system with an internet-based interface by integrating Internet technology, a Geographic Information System (GIS), and a hydrologic model. Taramelli et al. (2010) modeled the risk hurricane elements in potentially affected areas by a GIS system. Accurate estimation on the potential flooding area in a typhoon is critical for damage or loss mitigation. Basher (2006) and Twigg (2003) suggested that insufficient communication and lack of preparedness are always the cause of warning system failure. They both emphasized that an early warning system should be people-centered.

The purpose of this study is to assemble several existing technologies to develop a coastal flooding warning system. For warning purposes, future sea state scenarios are required. Wave and storm surge models are therefore essential in the system. In addition, field data are required for model calibration and assimilation. Experiences from historical records are also valuable as a reference. Furthermore, computer science was used to link the components. In this paper, the early warning system developed and applied for the Taiwanese coast is studied. In Sect. 2, the coastal damage caused by typhoons is presented. The components of the warning system are introduced theoretically in Sect. 3. In Sect. 4, the system is illustrated and the conclusion is given in the final Sect. 5.

\section{Coastal disasters caused by typhoons in Taiwan}

The IPCC AR4 report shows that the number of strong typhoons could increase in the northwestern part of the Pacific Ocean. Taiwan is an island located on the western edge of the Pacific Ocean in the center of the East-Asian island arc. Its location is a major typhoon site in the northwestern area of the Pacific Ocean, rendering Taiwan vulnerable to frequent disasters caused by typhoons. Overall, approximately 30 ty-

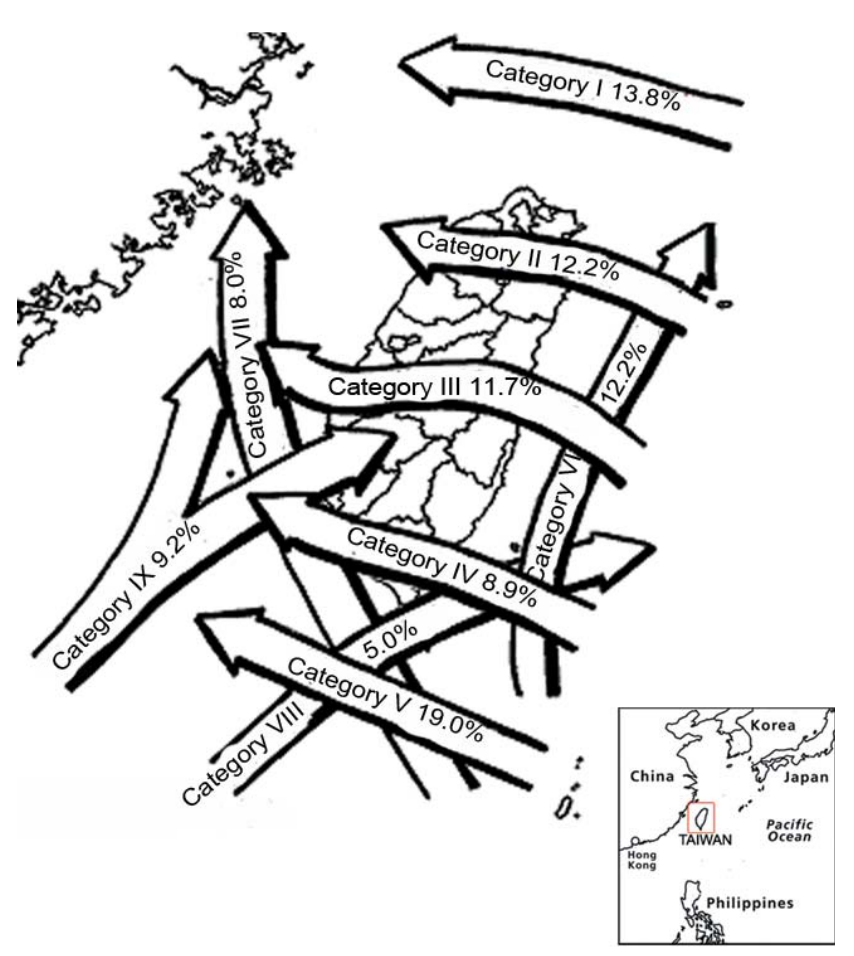

Fig. 1. Category of tracks of typhoons attack Taiwan.

phoons originate in the western part of the Pacific Ocean each year, of which an average of four to six pass through or influence Taiwan. In the past $100 \mathrm{yr}$, more than 400 typhoons have landed in or directly influenced Taiwan (Fig. 1). In certain years, Taiwan was subjected to a surge in the number of typhoons, such as in 2010, with 10 typhoons. The areas most affected by typhoons are low coastal regions, where more than half the population resides, with extensive infrastructure, buildings and businesses. Losses from typhoon-related disasters in Taiwan are substantial.

Most exposed populations in the world are protected from coastal flooding by various structural measures. The coastline of Taiwan's main island is approximately $1100 \mathrm{~km}$ long. Since the 1950s, concrete diking has been the commonly used protection technique in Taiwan. Currently, nearly $370 \mathrm{~km}$ of the Taiwanese coastline have been covered with sea dikes. Although improvements in the aesthetics of sea defenses have been actively pursued in recent years, sea dikes remain the most important structural measure for coastal flood mitigation and damage control against typhoons. Sea dikes will remain essential and indispensable to protect life and ensure continued agricultural production. Figure 2 shows the length of damaged sea dikes during typhoons in the past $30 \mathrm{yr}$ corresponding to the number of typhoons. In total, $150 \mathrm{~km}$ sea dikes have been damaged and repaired, that is, $5 \mathrm{~km}$ damaged per year. According to statistics by the Water Resources Agency in Taiwan, 22.3 million dollars have been invested for sea dike restoration in the past $10 \mathrm{yr}$. 


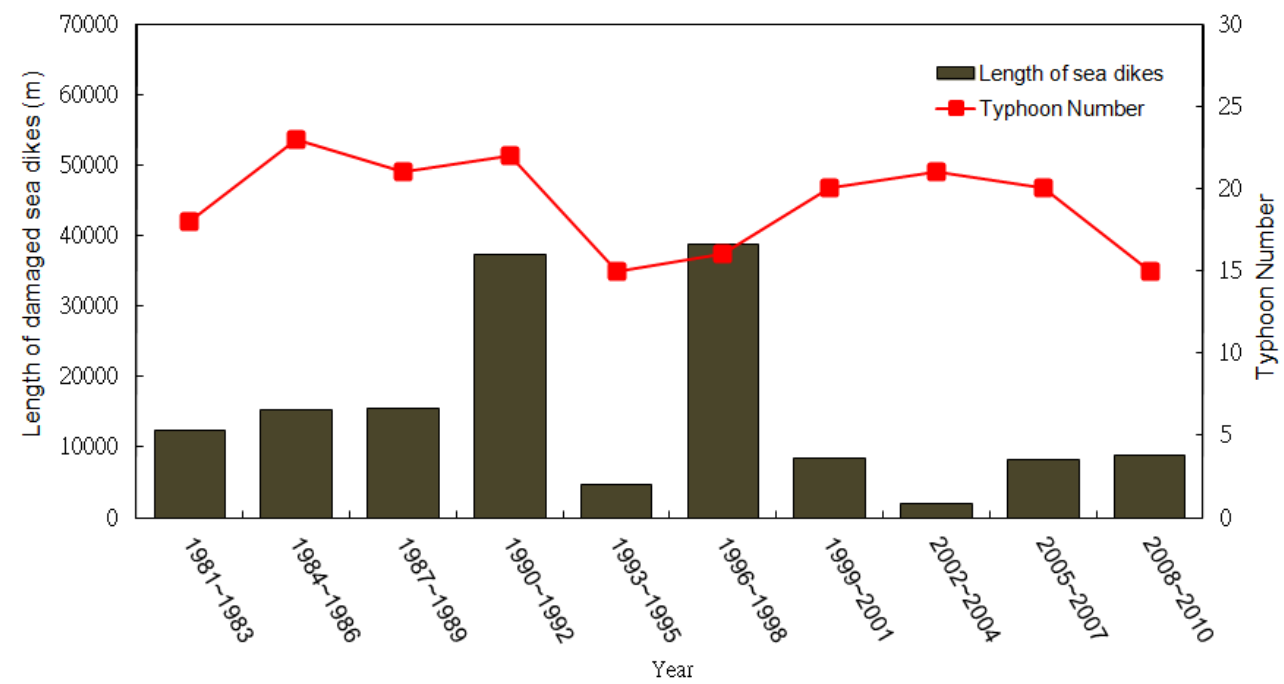

Fig. 2. Statistics of the damaged sea dyke from 1981 to 2010.

\section{Composition of the warning system}

\subsection{System framework}

Nations worldwide have increased their focus on establishing a warning system for the mitigation of and preparedness for coastal flooding hazards and their catastrophic impacts, for use by emergency managers, coastal zone managers, planners, and other decision makers. ISDR (2004) defined an early warning system as a system that provides timely and effective information through related institutions, which allows individuals exposed to a hazard to take action, to avoid or reduce risk and prepare for an effective response. Early warning systems exist for preparation against natural geophysical and biological hazards, complex sociopolitical emergencies, industrial hazards, personal health risks, and numerous other related risks. This study focuses on early warning systems for coastal flooding hazards.

An entire early warning system for natural hazards must comprise four factors including risk knowledge, a monitoring and warning service, dissemination and communication, and response capability. Because of the vulnerabilities of society to natural hazards, providing knowledge to people on the risks of relevant hazards is essential. The second factor, a monitoring and warning service, is a technical capacity to monitor hazard precursors for hazard progression forecasting and to issue warnings. The dissemination of understandable warnings and information on preventive measures is necessary. The last factor of the warning system is to provide information, plans, and capacity data to enable relevant authorities and those affected to take timely and appropriate action. This study focuses on the technical development of a monitoring and warning service. The coastal flooding early warning sys- tem developed in this study aims to provide past, current and future information as shown in Fig. 3. It is comprised of the following three parts: a real-time monitoring unit, an operational numerical modeling unit, and an information interface, as detailed below.

\subsection{Real-time monitoring network}

The key function of a coastal flood warning system is the real-time monitoring of sea conditions and marine meteorology. Real-time data can be used in various manners to evaluate coastal flood risks and issue flood warnings. To ensure early detection of hazardous sea conditions and to acquire data critical to real-time forecasts, a nationwide coastal ocean monitoring network has been established since 1997. The network comprises both in situ and remote sensing stations that are located in shallow water, as well as in open sea. They include 15 moored-type data buoys, 11 tide stations, 12 coastal weather stations, 2 microwave radar stations, and 5 optical camera stations. Figure 4 shows the locations of the stations in the network. Table 1 shows the composition and the functions of these instruments. Data of sea-state parameters (wave height, period, and direction; sea surface elevation; current) and marine meteorological elements (wind, air, and sea temperatures; barometric pressure) are obtained from these instruments. Other than the time series data, microwave radar stations acquire surface wave information with spatial coverage (Nieto Borge et al., 1999; Wu et al., 2011). The end-users of the proposed early warning system are the Water Resources Agency (WRA) in the central government and the River Bureau (RB) in local authority. Most decision makers lack knowledge for interpreting sea conditions. Field images taken by optical cameras in the field are the supporting information, providing visual coverage. 


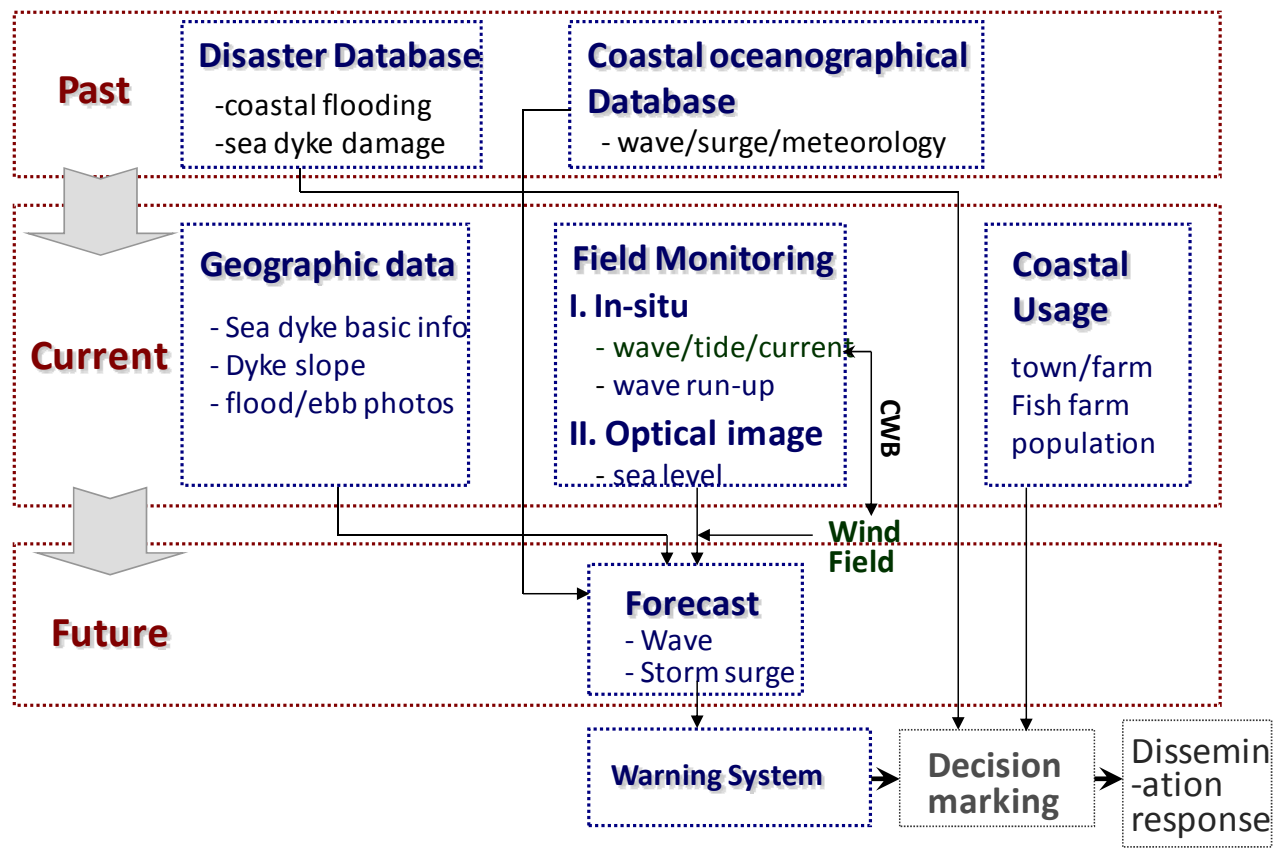

Fig. 3. Framework and internal link of the coastal flooding warning system.

Table 1. Composition of the monitoring network.

\begin{tabular}{lllll}
\hline Station type & Quantity & Observations & Location & Function \\
\hline Data buoy & 15 & $\begin{array}{l}\text { Waves, Wind, current, } \\
\text { Temperatures, Pressure }\end{array}$ & $\begin{array}{l}\text { Coastal ocean }(<100 \mathrm{~m}) \\
\text { and offshore }(>2000 \mathrm{~m})\end{array}$ & $\begin{array}{l}\text { - Model calibration and verification. } \\
\text { - Understand of real-time sea states }\end{array}$ \\
\hline Tide station & 11 & Sea water level & Along the coastline & $\begin{array}{l}\text { - Monitoring sea level in real-time } \\
\text { - Storm surge model verification }\end{array}$ \\
\hline $\begin{array}{l}\text { Coastal weather } \\
\text { station }\end{array}$ & 10 & Meteorological elements & Intertidal zone, coastline & - Monitoring coastal weather \\
& & & & $\begin{array}{l}\text { Data for typhoon tracking model } \\
\text { assimilation }\end{array}$ \\
\hline Radar station & 2 & Spatial wave condition & Coast high building & $\begin{array}{l}\text { - Monitoring waves in spatial } \\
\text { domain }\end{array}$ \\
\hline $\begin{array}{l}\text { Optical camera } \\
\text { station }\end{array}$ & 5 & $\begin{array}{l}\text { Sea surface movement, } \\
\text { overtopping }\end{array}$ & Coast high building & $\begin{array}{l}\text { - Visual coverage for lack } \\
\text { professional knowledge } \\
\text { decision makers }\end{array}$ \\
\hline
\end{tabular}

Data buoys are the most commonly used instrument for marine measurements in coastal oceans and at sea. They are developed and manufactured locally in Taiwan (Kao et al., 1999). Discus-shaped buoys with $2.5 \mathrm{~m}$ diameter were designed. Two anemometers are mounted on the mast of the buoy at approximately $3 \mathrm{~m}$ above the sea surface, equipped with sea and air temperature sensors and a barometer. The buoy payloads and light are typically powered by secondary batteries with solar charging and primary battery backup. For wave monitoring by data buoys, both inertia gyros and GPS systems are integrated to provide six degrees of freedom for acceleration, velocity, and inclination on three axes. GPS is used as a wave measurement auxiliary device (Doong et al., 2011). The recorded buoy movements of ocean surface waves are used to yield a wave directional spectrum using cross-spectrum analysis, detailing the characteristics of wave energy distribution on frequency and the direction of propagation. The directional spectra provide superior precision for building a wave forecast model and for application of data assimilation technology.

Since the coastal waters are a highly non-homogeneous area, $\mathrm{X}$-Band microwave radar systems that have $5 \mathrm{~km}$ radius 


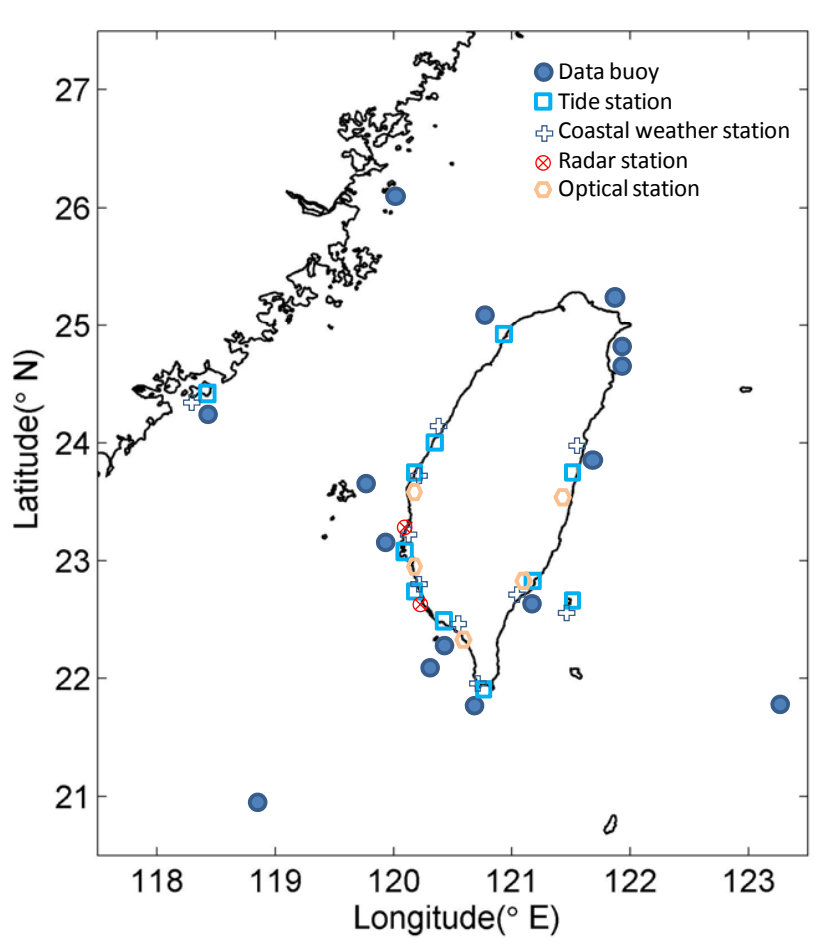

Fig. 4. Coastal and ocean monitoring network in Taiwan Waters.

coverage capability are installed in the monitoring network in order to provide spatial wave pattern (Wu et al., 2011), in additional to the point measurement by data buoys. The coastal weather stations that are equipped with automatic wind, pressure, temperature sensors and rainfall gauge are set up at the sea-land interface. The sampling rate is $2 \mathrm{~Hz}$ and the measurement interval is one hour. Further, the optical cameras are installed at the coast in order to monitor the overtopping of sea water. The images are transmitted to the system to provide live sea images for the decision markers in real-time.

In addition to data buoys, all other stations in the monitoring network are also equipped with a real-time data transmission system. For near-shore stations, field data are automatically transmitted to a quality check center by a cost-free radio telemetry or low-cost GSM (Global system for mobile communications) or GPRS (General packet radio service) cellular communication technology. However, because radio telemetry, GSM and GPRS signals reach only a limited distance, the telecommunication link with satellite is used for far offshore stations. Data transmission cost is one of the most important issues for long-term observation systems. A comparison, as displayed in Fig. 5, shows that GPRS is the best data transmission choice because of its low cost and reliability.

Data correctness is another crucial requirement for early warning systems. Quality control procedures are performed on automated data when the central control computer receives them. Automated data quality is assessed according

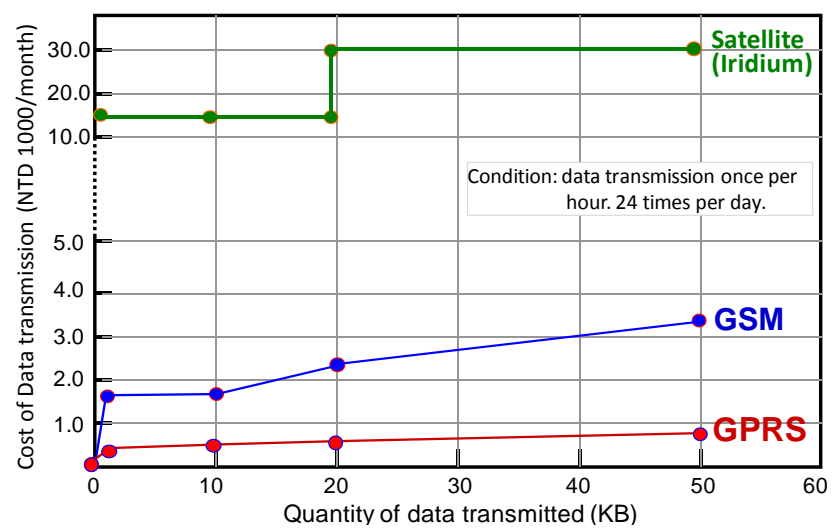

Fig. 5. Comparison of various data transmission costs.

to sensor limitation, time continuity, and internal consistency (Doong et al., 2007). After experienced data analysts conduct manual data verification, data are processed, formatted, and imported to the early warning system in less than $30 \mathrm{~min}$ after measurements.

\subsection{Operational numerical modeling}

Field observations provide actual sea conditions; however, numerical models are necessary to forecast the tendency of coastal sea conditions and which is necessary in an early warning system. Numerical ocean models have been widely studied in the research field. However an early warning system needs operational models. Performance of a numerical model from research use into an automatic, efficient, and non-breaking operation system is actually a complex procedure, for example the input of wind field. A typhoon wind field modelled after the Rankin-Vortex model (Holland, 1980 ) is adopted for research purposes. Although the modeled wind field was revised and applied recently (Holland, 2008; Taramelli et al., 2010), we suggest importing an analysis of a wind field from atmospheric models provided by the weather authority, regarding its suitability for mountainous area in Taiwan. Figure 6 shows the reasonable wind field derived by the atmospheric model. Another issue of developing an operational model in a warning system is the time consumption. Unlike the model execution time, which may not be a serious concern for the esearch stage, time is an essential consideration in a state of warning; therefore, fully operational and efficient models are necessary in an early warning system.

Coastal flooding occurs when storm water levels surpass the elevation of sea dikes. The storm level is the maximum water level that is reached on the sea dike. It is contributed by the astronomical tidal level, storm surge height, wind setup, wave run-up, and potentially the direct impact of ocean waves. A wave model and a storm surge model are therefore both required in a coastal flooding early warning system. 

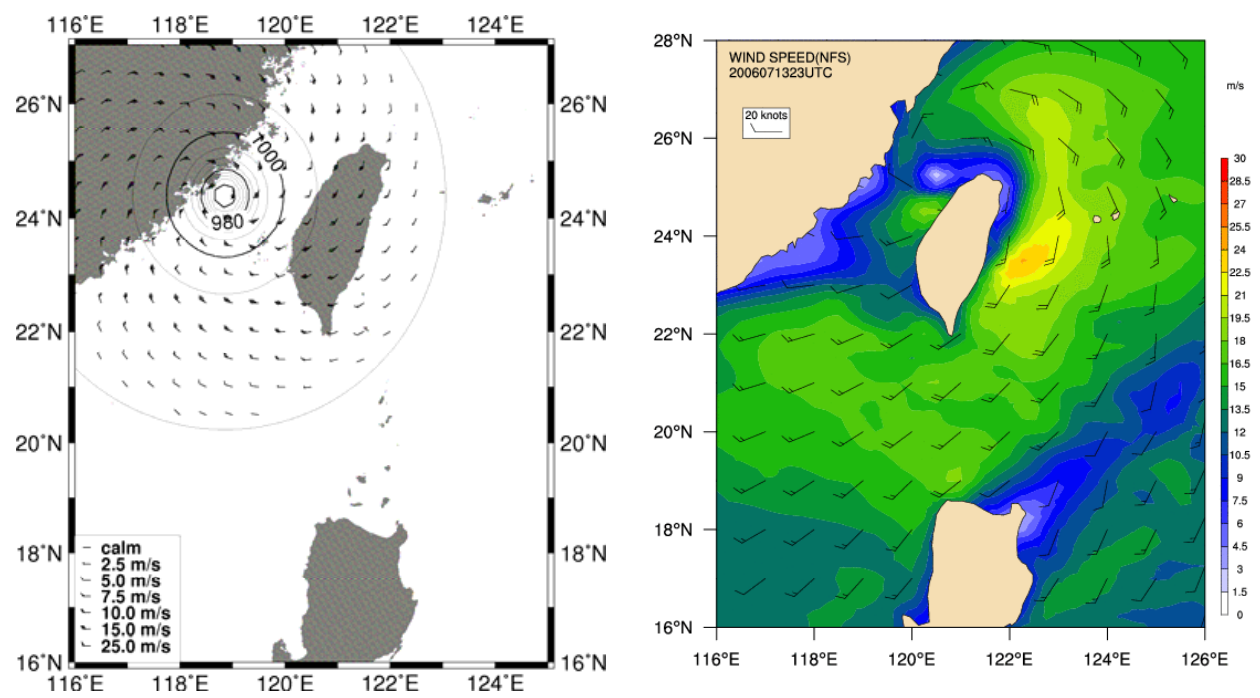

Fig. 6. Comparison of modeled wind field (left) and atmospheric model derived (AMD) wind field (right). The AMD wind field reasonably simulates the wind distortion when a typhoon passes through the high mountains in central Taiwan.

Current numerical wind-wave prediction models for oceans and shelf seas are based on the spectral energy balance equation, which describes the space-time evolution of a two-dimensional spectrum with source terms that account for wind-wave interaction, nonlinear wave-wave interaction, wave-current interaction, and dissipation. A wind-wave propagation model for coastal areas differs essentially from a model that can be applied to deeper waters because the small depths cause different processes to be dominant, more specifically, depth-induced breaking. Therefore, the wave model within the warning system consists of large-scale, regional, nested grids. In this study, the NOAA WAVEWATCH III (NWWIII) model (Tolman, 1991) is used for simulating waves in the East Asia domain, and the SWAN model (Booij et al., 1999) is used for simulating coastal waves because it has high spatial resolution and uses superior physics calculations for shallow water areas. Ou et al. (2002) has demonstrated the capability of typhoon wave simulation using SWAN. The Princeton Ocean Model (POM) (Blumberg and Mellor, 1987) is used for storm surge forecasting in the proposed warning system.

For the early coastal flooding warning system developed in Taiwan, wind fields are imported twice per day, at 00:00 UTC and 14:00 UTC, by the Central Weather Bureau (CWB). The temporal resolution of wind fields is $1 \mathrm{~h}$, and the spatial resolution is $45 \mathrm{~km}$ for the East Asian domain, but $15 \mathrm{~km}$ for the near-Taiwan domain. After the central control computer of the warning system receives the wind field data, NWWIII is triggered to provide the two-dimensional wave spectra on boundaries for the regional SWAN model. NWWIII is run operationally with a grid spacing of $45 \mathrm{~km}$, followed by SWAN to obtain a coastal wave forecast model $72 \mathrm{~h}$ ahead. The spatial resolution of the bathymetry used in SWAN is

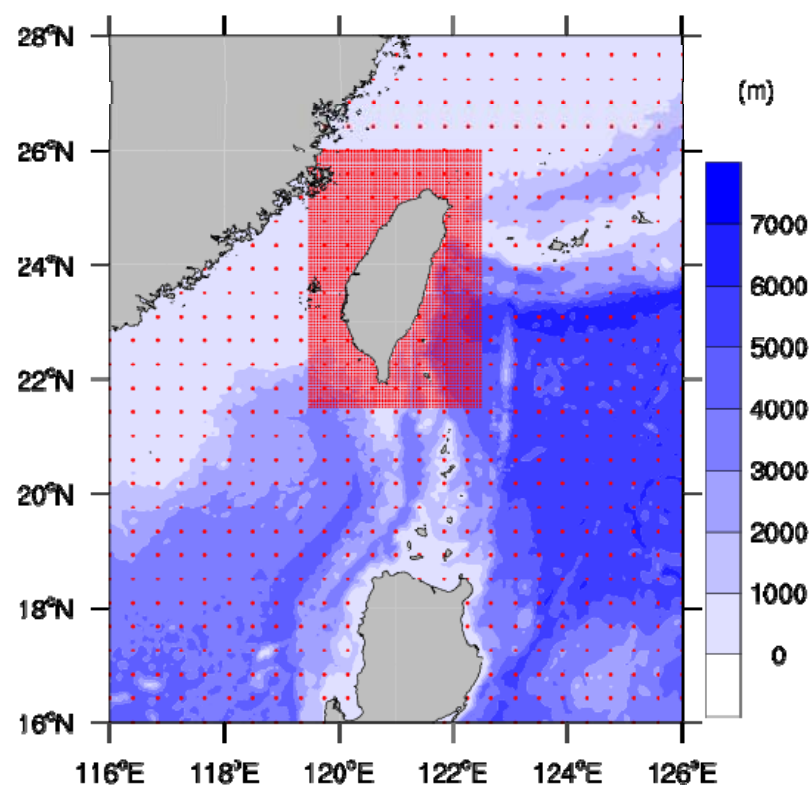

Fig. 7. Nested grids used for numerical wave models. Whole domain - NWWIII model, grid size is $45 \mathrm{~km}$. Central regional domain - SWAN, grid size is $0.5 \mathrm{~km}$.

$5 \mathrm{~km}$ for the coastal ocean, though occasionally condensed to $500 \mathrm{~m}$ for certain small coastal areas for wave run-up computation. Figure 7 shows the grid distribution for wave models. When wave models run on one computer, the POM model runs on a separate computer to provide the storm surge height during typhoons. An empirical formula that correlates the storm surge height and the distance between station locations to the typhoon is calibrated and used as a backup demand in 


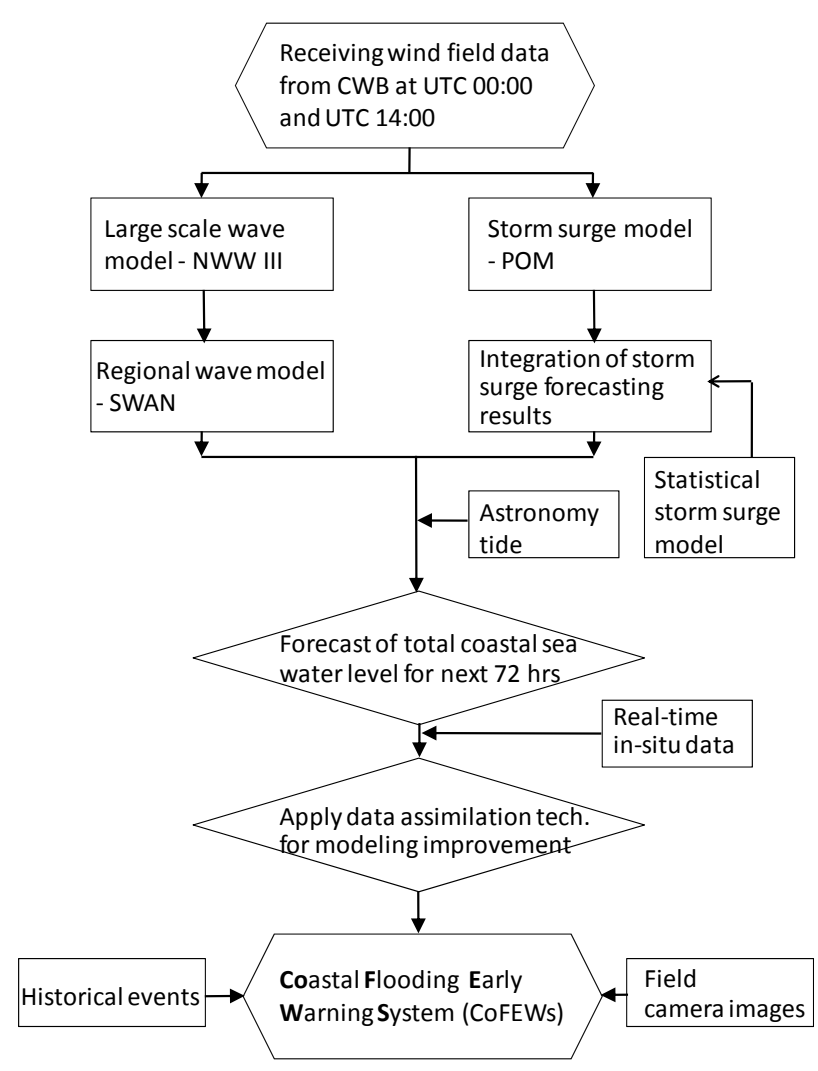

Fig. 8. Flowchart of the operational models.

the warning system. The models used in this warning system are listed in Table 2. The flowchart of the operational models and system elements and their interlinks is shown in Fig. 8.

Waves and storm surges simulated by the numerical models have been extensively verified before the operation of the proposed warning system. Figure 9 shows the significant wave height simulation at Longdong in the northeastern coastal ocean of Taiwan for the typhoon season of 2006. The correction coefficient between the simulated wave heights with the measurements is 0.66 . Results of verification from other stations range from 0.55 to 0.76 . This outcome is not wholly satisfying. Figure 10 shows another example of the wave height verification during typhoon Songda (2011) at Longdong. It is found that the regular simulation of waves yields a reasonable result for the wave growth stage, but the maxima wave height is always underestimated, and simulation of the decaying sea state is inadequate. The data assimilation was performed to improve the accuracy of model simulation by using the univariate optimal interpolation (OI) procedure on constant depth surfaces by interpolating appropriate model variables from the $\sigma$-levels to the depth levels. The new values were interpolated back to the original $\sigma$-coordinates (Daley, 1991). Real-time data from buoys are used for assimilation. An example of the comparative results is shown in Fig. 11. The model with simulated wave heights that uses the assimilation technique has stronger agreement with actual measurements than the direct model does. Other verifications are shown in Fan (2008). Data assimilation technology improves the simulation, and is employed in the warning system.

\section{The Coastal Flooding Early Warning System (CoFEWs)}

\subsection{Nationwide system}

In this study, we developed a coastal flooding early warning system to provide timely and correct information for imminent and dangerous circumstances, with which appropriate action could be taken in advance to reduce potentially affected risks. The warning system may be applied on the national scale or even on local scales. The WRA is responsible for making decisions and RB is distributing hazard relief items in Taiwan. The Coastal Flooding Early Warning System (CoFEWs) is for use by the WRA and RB, but is not open to the public. Considerations for constructing the proposed warning system were as follows: accurate information, simplicity in operation, user-friendly interface, and web-based. The system was developed using Microsoft ASP.NET technology with an MS SQL-Server. Four desktop computers are used for the system. One for wave modling, the second one for storm surge modeling, the third is the central control computer including the information system and historical database, and the fourth computer is for system backup. The web-based system is designed for its easiness to maintain, and technical support can be provided by teams located in different cities or countries.

Figure 12 shows the main page of CoFEWs. Four chief parts are on this page, which are the Real-time Sea States (RSS), the Forecast Storm Level (FSL), the Live Video Image (LVI), and the Historical Typhoon Events (THE). RSS shows real-time sea conditions including wave conditions (height, period, and direction), tide condition (astronomical tide height), and meteorological conditions (wind, temperature, and pressure). The data are updated hourly, when new measurements are transmitted to the system server. LVI is arranged at the bottom left and bottom right windows. The system manager and the authorized user have remote control access to the cameras when they select the image window and identify the status. LVI is designed to help users understand sea conditions using images. FSL is the kernel of CoFEWs. The storm level is the total sea water levels (TSWL) of locations estimated from the summation of the astronomical tidal level, storm surge height, half of the significant wave height, and the wave run-up height. TSWL in the eastern and western locations of Taiwan are listed in the upper left and upper right tables in the main page. The tables show a comparison of the TSWLs with the alarm level (entitled Dyke El.), which is located in the second column, to assess 
Table 2. Models used in the warning system.

\begin{tabular}{|c|c|c|}
\hline Model & Purpose & Domain \\
\hline NWWIII & Boundary wave field for inputting to coastal model & East Asia: $116^{\circ} \mathrm{E} 126^{\circ} \mathrm{E} ; 16^{\circ} \mathrm{N} 28^{\circ} \mathrm{N}$ \\
\hline SWAN & Forecast coastal waves & Taiwan nearshore: $119.5^{\circ} \mathrm{E} 122.5^{\circ} \mathrm{E} ; 21.5^{\circ} \mathrm{N} 26^{\circ} \mathrm{N}$ \\
\hline POM & Forecast storm surge heights & Taiwan nearshore: $119.5^{\circ} \mathrm{E} 122.5^{\circ} \mathrm{E} ; 21.5^{\circ} \mathrm{N} 26^{\circ} \mathrm{N}$ \\
\hline
\end{tabular}

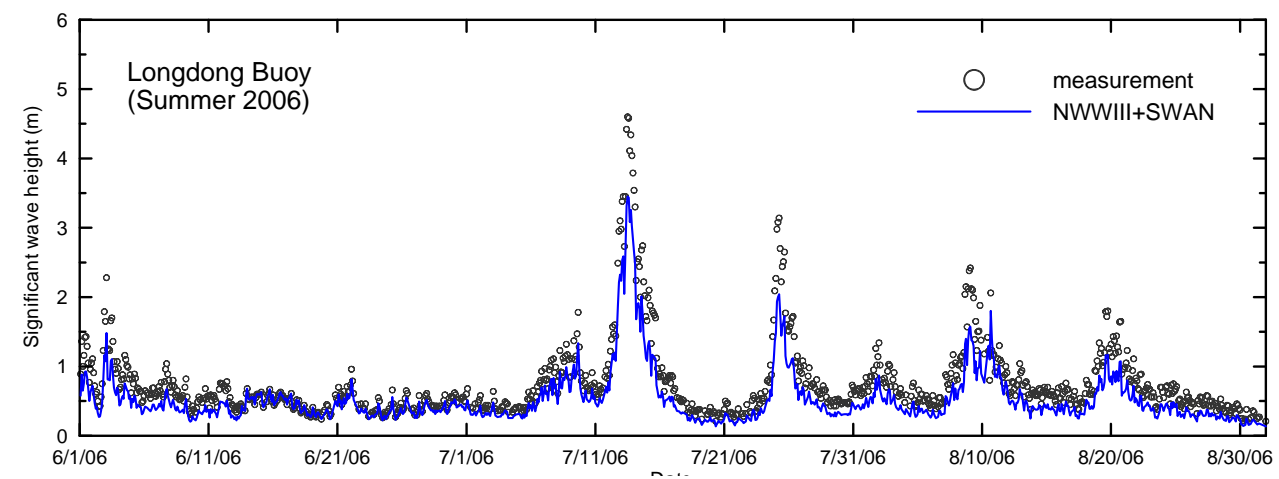

Fig. 9. Verification of long-term wave simulation (summer in 2006).

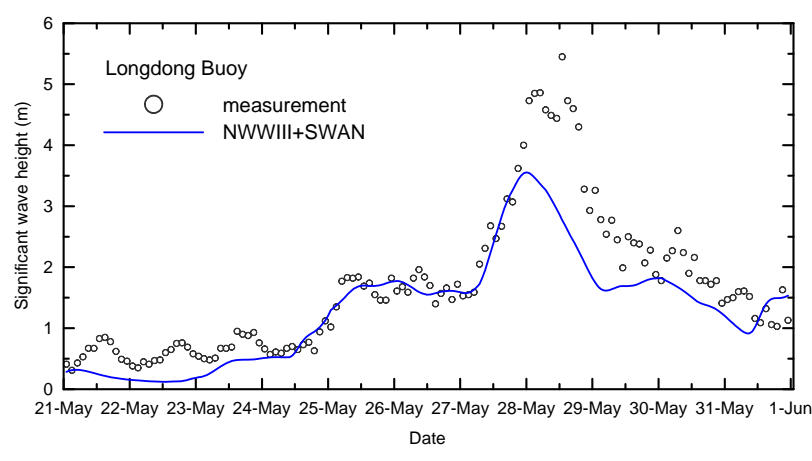

Fig. 10. Verification of wave simulation for the period of typhoon Songda in 2011 .

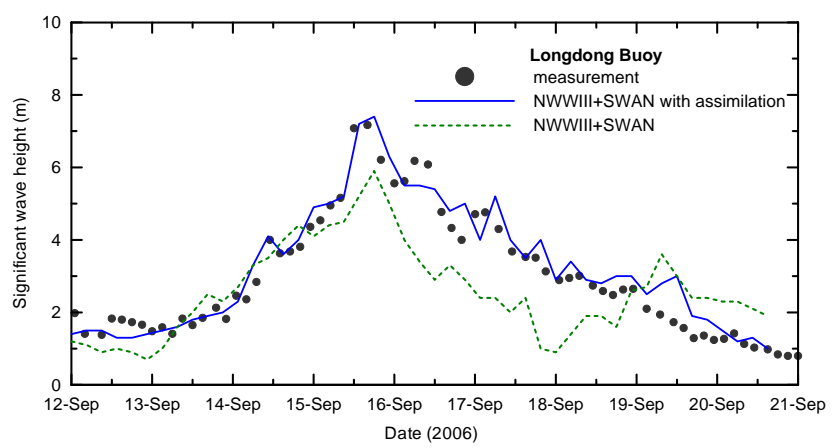

Fig. 11. Improvement of wave forecast by data assimilation technique. the possibility of overtopping. The WRA defines alarm levels, which are normally set at a certain distance to the top of the sea dykes, depending on the protected interests situated on the other side of the dyke. The overhead function scroll of the table entitled Forecast Time enables forecast time selection. TSWLs change according to the selection. CoFEWs is designed to show forecasting results $6 \mathrm{~h}$ ahead which is enough for decision-marking. When the overtopping condition is met, the status column in the table displays a warning notification in red. The information located at the bottom of the main page details past damages caused by typhoons that share a similar track with one in the present. Occasionally, historical experiences have an even higher referential value than those provided by the model using complex computations.

\subsection{The regional system}

The main page of CoFEWs is mainly used by the WRA in the central government. It helps the WRA study coastal conditions nationwide. The local RB uses a regional subsystem, as displayed in Fig. 13, which shows one coastal zone in the central map of RSS of CoFEWs. The regional warning system was developed using a similar framework, but with more detailed data. The database on sea dykes including the length, slope, elevation, and photos are collected and imported to the subsystem, as shown in Fig. 14 when one clicks the sea dyke name at bottom-right window of Fig. 13. Ten regional subsystems are currently used to observe the entire Taiwanese coastline. Some are equipped with a wave runup monitoring camera. The regional subsystem of CoFEWs 


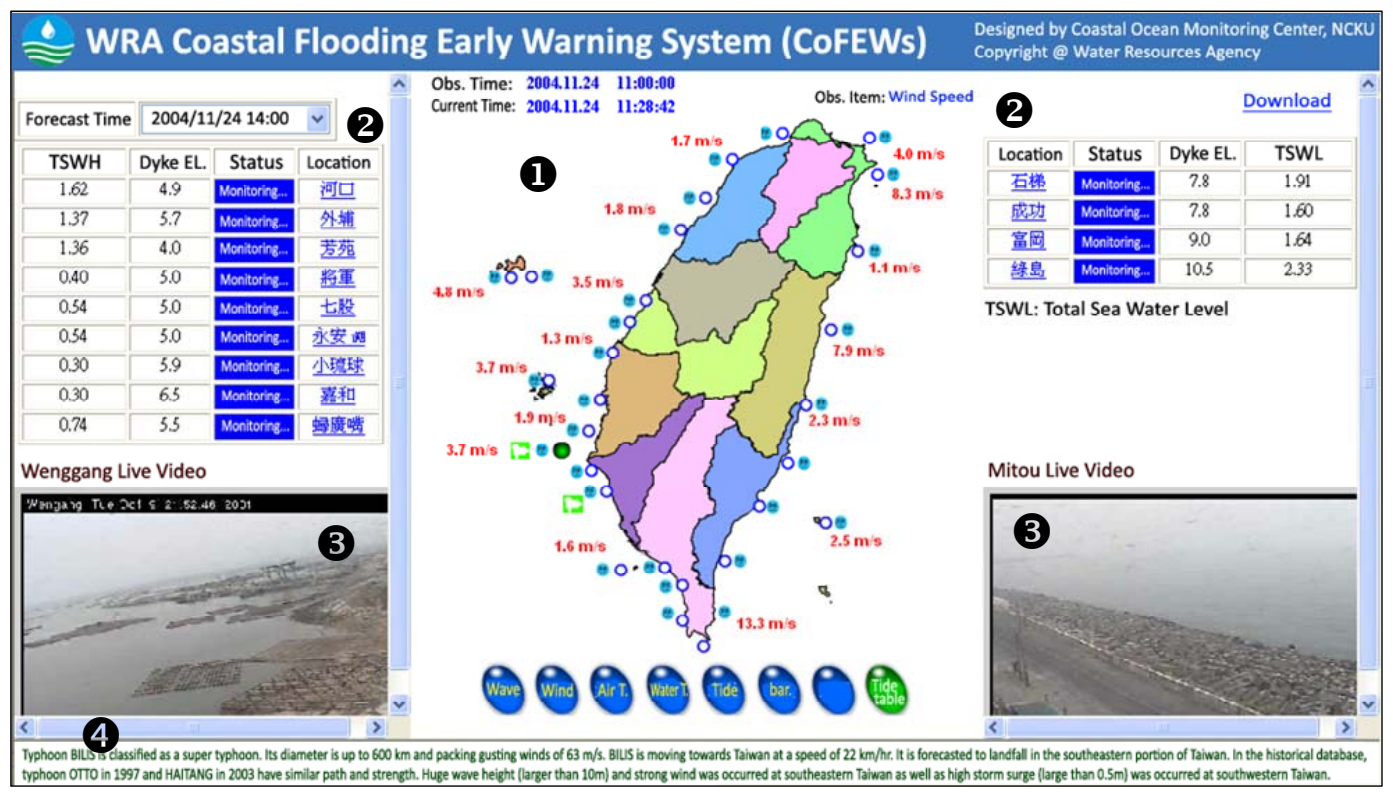

Fig. 12. Main page of CoFEWs. Four parts are presented in this page. They are $\mathbf{0}$ Real-time Sea States (RSS); 2 Forecast Storm Level (FSL); 3 Live Video Image (LVI); and 4 Historical Typhoon Events (THE).

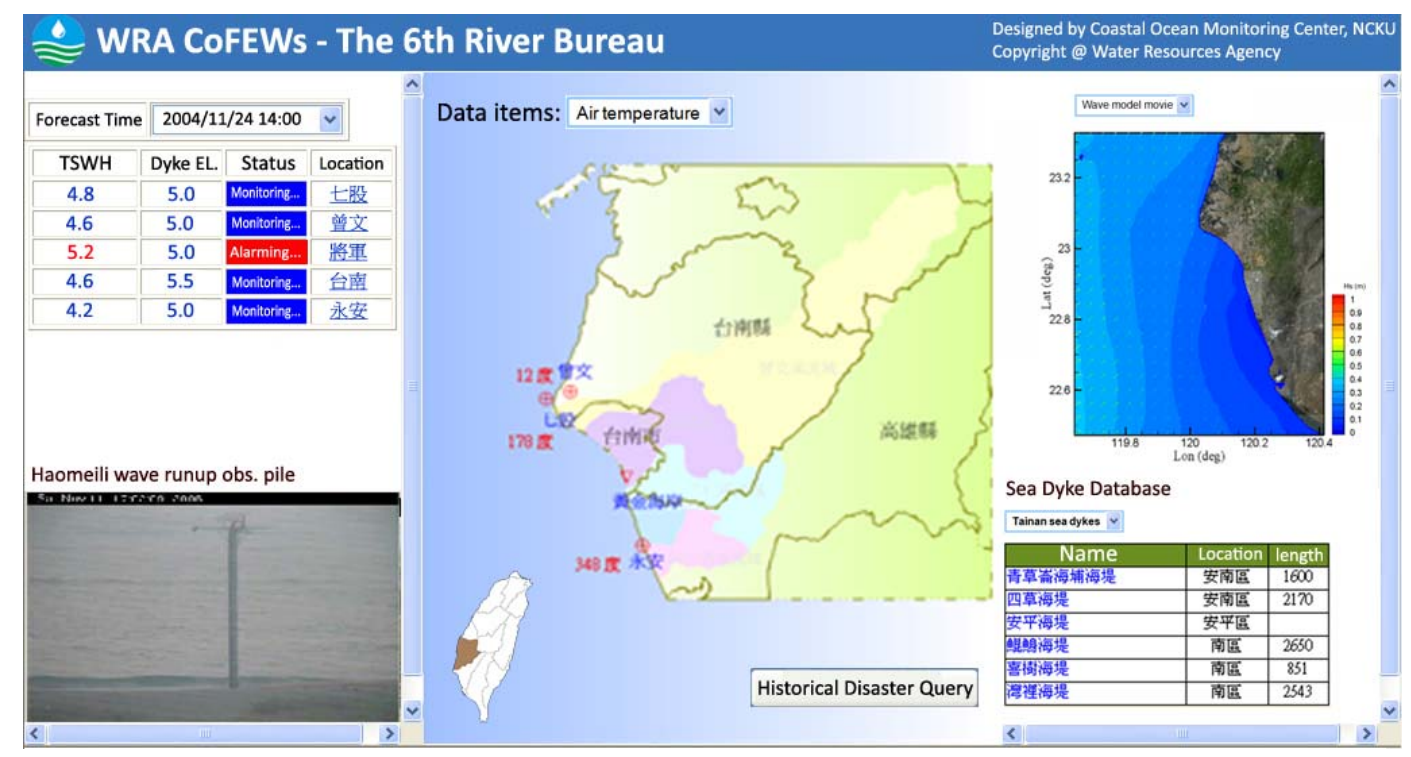

Fig. 13. Regional system of CoFEWs - Page for the 6th River Bureau.

is an action system that is used during typhoons. Both the CoFEWs and its subsystem were originally designed using the native language, and they are in operation daily.

\subsection{Case study: Typhoon Haitang}

Typhoon Haitang was a category 5 super typhoon in 2005, which struck the northwestern part of the Pacific Ocean. It moved westward and created a landfall in Hualien, Taiwan, on 18 July, as shown in Fig. 15. Operational models were running prior to the arrival of the typhoon. Figure 11 shows that the forecasted wave height in Longdong indicated good agreement with the measurements by applying assimilation. On the western coast of Taiwan, a high wave runup occurred (Fig. 16). The joint effects of wind, waves, and high tide caused the total sea water level to overtop the sea dykes and alarmed the regional system, as shown in Fig. 13. 


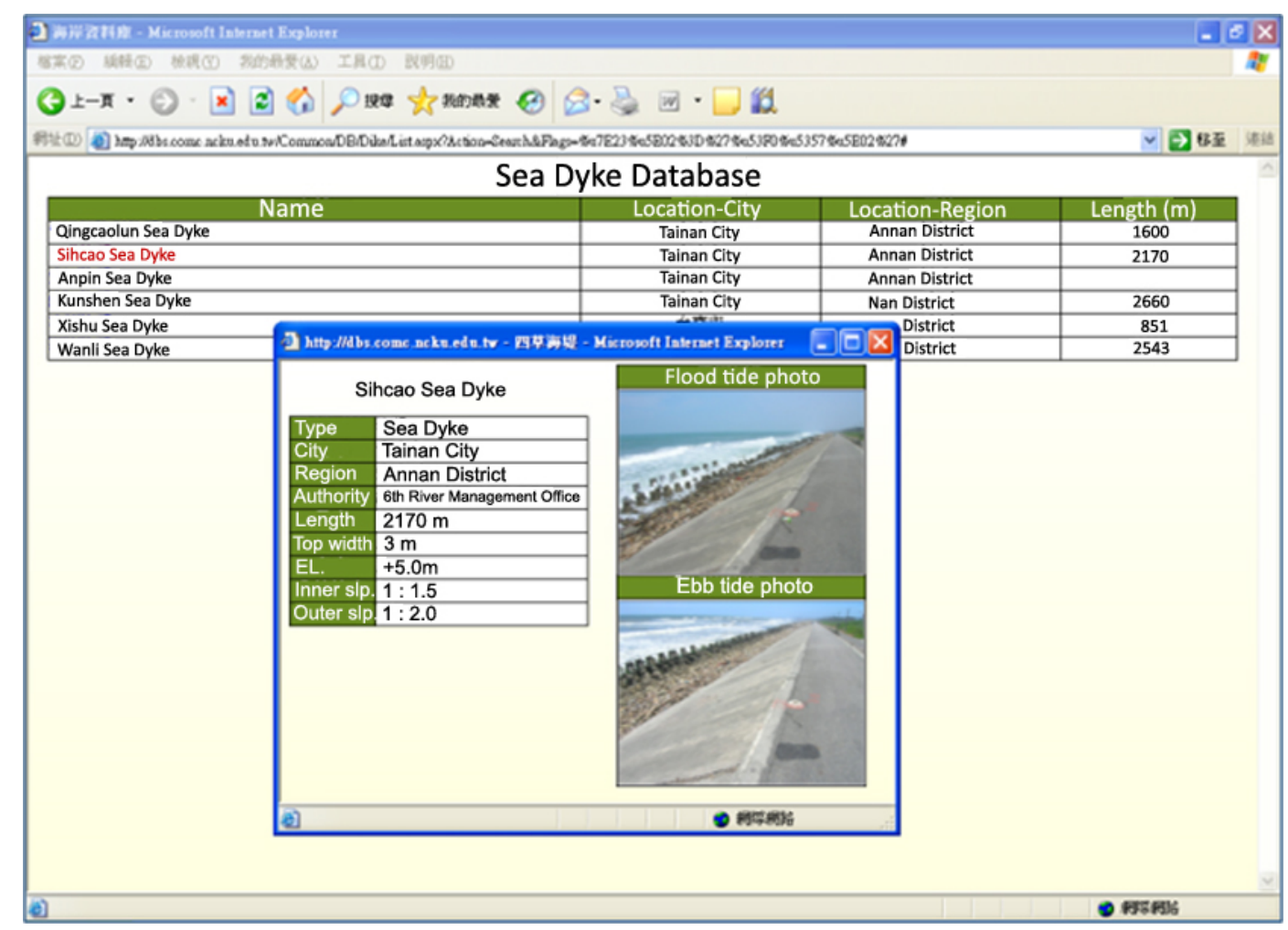

Fig. 14. Window of detail data of queried sea dyke.

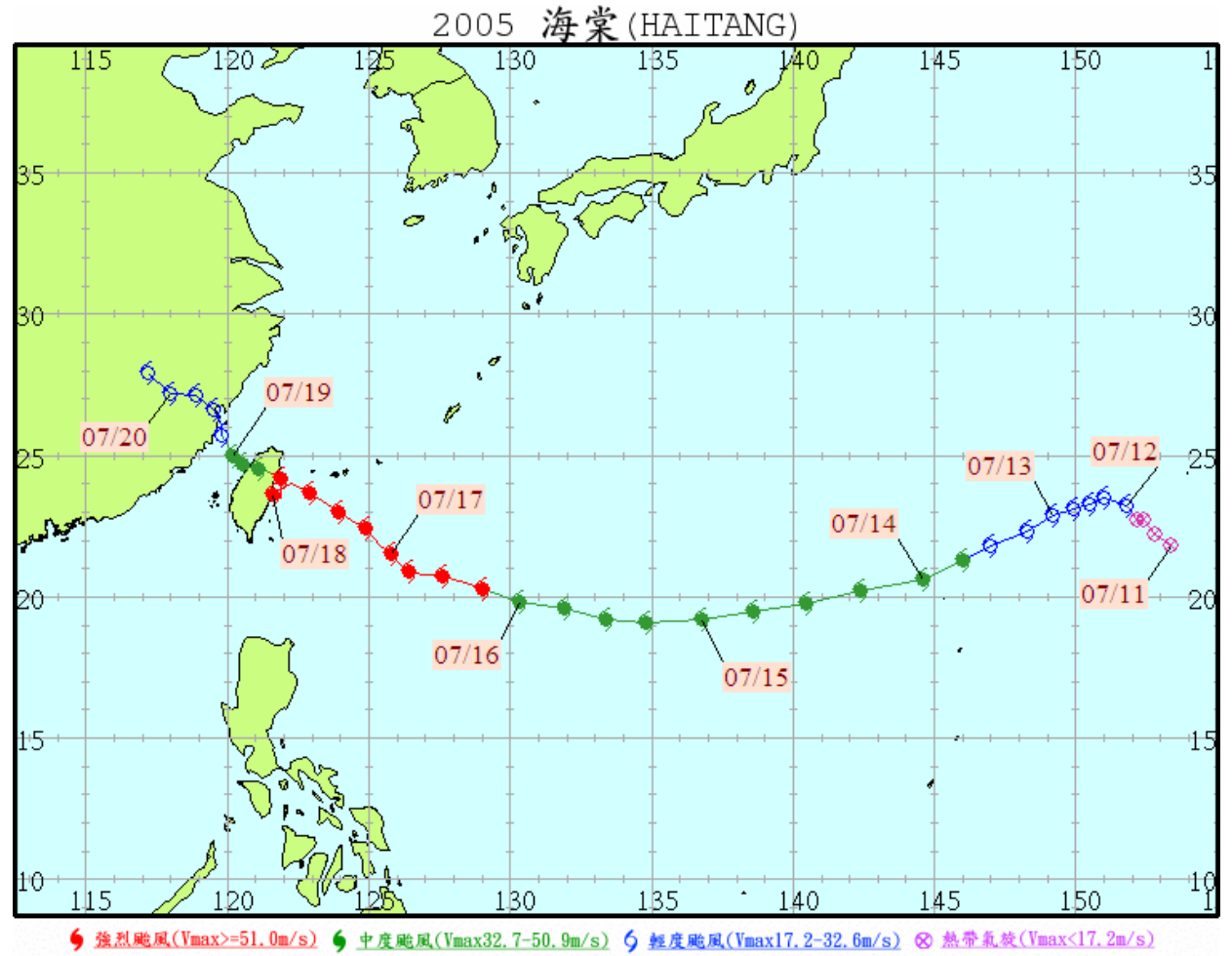

Fig. 15. Track of typhoon Haitang in 2005. 


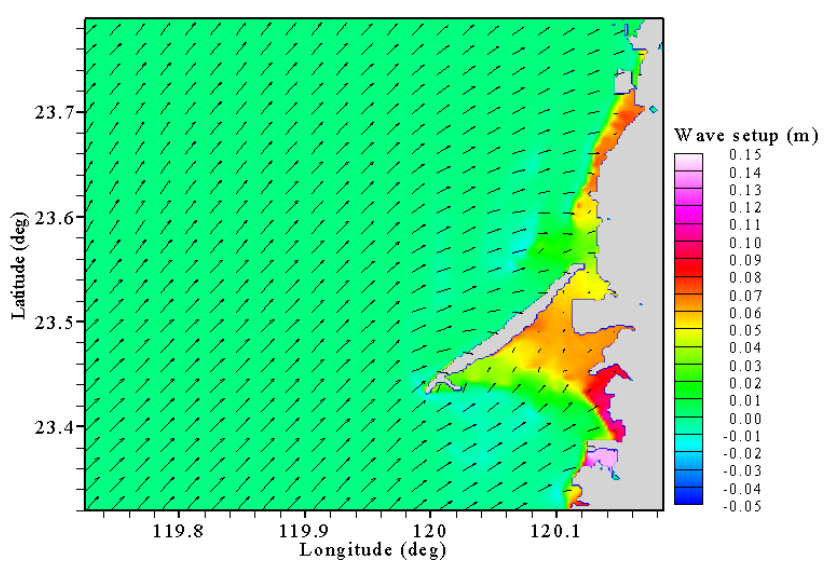

Fig. 16. Wave height and runup presented by the operational models.

\section{Conclusions}

The frequency of natural disasters may be increasing because of growing global change. The magnitude of a disaster depends on the intensity of a natural hazard, in addition to the effectiveness of prevention mitigation actions. Natural hazard events cannot be prevented from occurring, but their impacts on people and property can be reduced if accurate information can be provided to people in a timely manner. An early warning system is therefore essential.

Taiwan, located at the major site of typhoons in the NW Pacific, is frequently threatened by typhoons. A large amount of coastal defense has failed, life and property has been lost in the past thirty years in Taiwan. Global climate change is increasing the frequency and strength of typhoons. The threat from typhoons and disasters is increasing. In this study, we have developed the warning system CoFEWs to mitigate coastal flooding in Taiwan. First, the users of the system must be defined clearly. The warning system functions according to the background of a user and to the purpose of using the system. Because users of the CoFEWs are administrators without professional academic backgrounds, a userfriendly interface with a single page of information, without requiring numerous clicks and video and movie presentations for measurements and model results has been designed. Second, the functionality of the system must be clearly defined. CoFEWs monitor sea conditions and forecast overtopping possibilities on sea dykes. To achieve this objective, a real-time coastal watch network and numerical modeling are the basis of the system. We constructed the CoFEWs by integrating an operational East Asian scale NWWIII model and the regional SWAN model for coastal wave forecasting, in addition to the POM model for storm surge prediction. Accurate forecasting was verified in the wave growth stage, but poor results were obtained for the wave subsiding period in a typhoon. The maximal significant wave heights during typhoons are occasionally not forecasted properly. We improved this problem by applying data assimilation technology in CoFEWs. The operational model should not only pursue the accuracy of the simulation, but balance it with computational efficiency. Decision makers cannot wait for 5\% simulation improvements, but require reasonable model results immediately. Real-time data are very necessary to import into the system for assimilation purposes, except for their direct function of monitoring the coastal sea conditions. The web-based warning system presented contains the main nationwide information page and a regional subsystem. Applying the system during Typhoon Haitang in 2005 and for numerous other typhoons thereafter has verified its accuracy and applicability.

Acknowledgements. This study is the partial outcome of the THESEUS (Innovative technologies for safer European coasts in a changing climate) project supported by the EC seventh framework programme (FP7) under the Grant agreement no.: 244104. Financial support is provided by the National Science Council of Taiwan (NSC 98-2923-I-006-001-MY4). Thanks to Mr. Tzu-Lien Cheng for his great help on the development of ther warning system through his excellent information technology. The authors also thank the Water Resources Agency for long-term support of the development of the early warning system and using it. In addition, the authors would like to give great thanks to the colleagues of COMC at NCKU for their efforts on the deployment and maintenance of the monitoring instruments. Finally, we greatly appreciate Fernando Mendez for his invitation to publish this paper.

Edited by: F. J. Mendez

Reviewed by: A. Taramelli and M. Gomez

\section{References}

Basha, E. and Rus, D.: Design of early warning flood detection systems for developing countries, in: Proceedings of the Conference on Information and Communication Technologies and Development, Bangalore, India, 11-20, 15-16 December 2007.

Basher, R.: Global early warning systems for natural hazards: systematic and people-centred, Philos. T. R. Soc. A, 364, 21672182, 2006.

Blumberg, A. F. and Mellor, G. L.: A description of a three-dimensional coastal ocean circulation model, in: ThreeDimensional Coastal Ocean Models, edited by: Heaps, N. S., American Geophysical Union, Washington, DC, 1-16, 1987.

Booij, N., Ris, R., and Holthuijsen, L.: A third-generation wave model for coastal regions I. Model description and validation, J. Geophys. Res., 104, 7649-7666, 1999.

Daley, R.: Atmospheric Data Analysis, Cambridge Univ. Press, New York, USA, 1991.

Doong, D. J., Chen, S. H., Kao, C. C., and Lee, B. C.: Data quality check procedures of an operational coastal ocean monitoring network, Ocean Eng., 34, 234-246, 2007.

Doong, D. J., Lee, B. C., and Kao, C. C.: Wave measurement using GPS velocity signal, Sensors, 11, 1043-1058, 2011.

Doornkamp, J. C.: Coastal flooding, global warming and environmental management, J. Environ. Manag., 52, 327-333, 1998. 
Fan, Y. M.: Spectral wave data assimilation in SWAN wave model, $\mathrm{PhD}$ thesis of National Cheng Kung University, Tainan, Taiwan, 2008.

Holland, G. J.: An analytical model of the wind and pressure profiles in hurricanes, Mon. Wea. Rev., 108, 1212-1218, 1980.

Holland, G. J.: A revised hurricane pressure-wind model, Mon. Wea. Rev., 136, 3432-3445, 2008.

Holz, K. P., Hildebrandt, G., and Weber, L.:, Concept for a webbases information system for flood management, Nat. Hazards, 38, 121-140, 2006.

ISDR: Terminology: basic terms of disaster risk reduction, International Strategy for Disaster Reduction Press, Geneva, Switzerland, 2004.

Kao, C. C., Chuang, L. Z. H., Lin, Y. P., and Lee, B. C.: An introduction to the operational data buoy system in Taiwan, in: Proceedings of the International MEDCOAST Conference on Wind and Wave Climate of the Mediterranean \& the Black Sea, Antalya, Turkey, 33-39, 9-13 November 1999.

Katuk, N., Ku-Mahamud, K. R., Norwawi, N., and Deris, S.: Webbased support system for flood response operation in Malaysia, Disaster Prevention and Management, 18, 327-337, 2009.

Kaya, Y., Stewart, M., and Becker, M.: Flood forecasting and flood warning in the firth of Clyde, UK, Nat. Hazards, 36, 257-271, 2005.

Nayak, S. and Kumar, T. S.: Indian tsunami warning system, In: Proceedings of the International Archives of the Photogrammetry, Remote Sensing and Spatial Information Sciences, 37, Beijing, China, 1501-1506, 3-11 July 2008.

Nieto Borge, J. C., Reichert, K., and Dittmer, J.: Use of nautical radar as a wave monitoring instrument, Coast. Eng., 37, 331342, 1999

Ou, S. H., Liau, J. M., Hsu, T. W., and Tzang, S. Y.: Simulating typhoon waves by SWAN wave model in coastal waters of Taiwan, Ocean Eng., 29, 947-971, 2002.
Parker, D. and Fordham, M.: An evaluation of flood forecasting, warning and response systems in the European Union, Water Resour. Manag., 10, 279-302, 1996.

Plessis, L. A.: A review of effective flood forecasting, warning and response system for application in South Africa, Water SA, 28, 129-137, 2002.

Solomon, S. M. and Forbes, D. L.: Coastal hazards and associated management issues on South Pacific Islands, Ocean Coast Manag., 42, 523-554, 1999.

Taramelli, A., Melelli, L., Pasqui, M., and Sorichetta, A.: Modelling risk hurricane elements in potentially affected areas by a GIS system, Geomatics, Natural Hazards and Risk, 1, 349-373, 2010.

Taubenböck, H., Goseberg, N., Setiadi, N., Lämmel, G., Moder, F., Oczipka, M., Klüpfel, H., Wahl, R., Schlurmann, T., Strunz, G., Birkmann, J., Nagel, K., Siegert, F., Lehmann, F., Dech, S., Gress, A., and Klein, R.: "Last-Mile" preparation for a potential disaster - Interdisciplinary approach towards tsunami early warning and an evacuation information system for the coastal city of Padang, Indonesia, Nat. Hazards Earth Syst. Sci., 9, 15091528, doi:10.5194/nhess-9-1509-2009, 2009.

Thumerer, T., Jones, A. P., and Brown, D.: A GIS based coastal management system for climate change associated flood risk assessment on the east coast of England, Int. J. Geogr. Inf. Sci., 14, 265-281, 2000.

Tolman, H. L.: A third-generation model for wind waves on slowly varying, unsteady and inhomogeneous depths and currents, J. Phys. Oceanogr., 21, 782-797, 1991.

Twigg, J.: The human factor in early warnings: risk perception and appropriate communications, in: Early Warning Systems for Natural Disaster Reduction, edited by: Zschau, J. and Küppers, A. N., Springer Verlag, Heidelberg, 2003.

Wang, X. H. and Du, C. M.: An Internet based flood warning system, J. Environ. Informatics, 2, 48-56, 2003.

Wu, L. C., Chuang, L. Z. H., Doong, D. J., and Kao, C. C.: Quantification of non-homogeneity from ocean remote sensing image using two-dimensional continuous Wavelet transform, Int. J. Remote Sens., 32, 1303-1318, 2011. 